\title{
PDGF signaling pathway in hepatic fibrosis pathogenesis and therapeutics (Review)
}

\author{
HUA-ZHONG YING $^{1}$, QIN CHEN ${ }^{2}$, WEN-YOU ZHANG ${ }^{1}$, HUAN-HUAN ZHANG $^{1}$, \\ YUE MA ${ }^{1}$, SONG-ZHAO ZHANG ${ }^{2}$, JIE FANG ${ }^{1}$ and CHEN-HUAN YU ${ }^{1}$ \\ ${ }^{1}$ Key Laboratory of Experimental Animal and Safety Evaluation, Zhejiang Academy of Medical Sciences, \\ Hangzhou, Zhejiang 310013; ${ }^{2}$ Department of Clinical Laboratory Medicine, Second Affiliated Hospital, \\ Zhejiang University College of Medicine, Hangzhou, Zhejiang 310009, P.R. China
}

Received September 23, 2016; Accepted July 20, 2017

DOI: $10.3892 / \mathrm{mmr} .2017 .7641$

\begin{abstract}
The platelet-derived growth factor (PDFG) signaling pathway exerts persistent activation in response to a variety of stimuli and facilitates the progression of hepatic fibrosis. Since this pathway modulates a broad spectrum of cellular processes, including cell growth, differentiation, inflammation and carcinogenesis, it has emerged as a therapeutic target for hepatic fibrosis and liver-associated disorders. The present review exhibits the current knowledge of the role of the PDGF signaling pathway and its pathological profiles in hepatic fibrosis, and assesses the potential of inhibitors which have been investigated in the experimental hepatic fibrosis model, in addition to the clinical challenges associated with these inhibitors.
\end{abstract}

\section{Contents}

1. Introduction

2. PDGF and the PDGF receptor (PDGFR)

3. Biological functions of PDGF and PDGFR

4. PDGF signaling pathway

5. Targeting the PDGF signaling pathway in hepatic fibrosis treatment

6. Future challenges and prospects

7. Conclusion

\footnotetext{
Correspondence to: Professor Chen-Huan Yu, Key Laboratory of Experimental Animal and Safety Evaluation, Zhejiang Academy of Medical Sciences, 182 Tianmushan Road, Hangzhou, Zhejiang 310013, P.R. China

E-mail: yuchenhuan2002@163.com
}

Key words: platelet-derived growth factor isoforms, hepatic fibrosis, signaling pathway, targeted drug, natural product, synergistic effect

\section{Introduction}

Hepatic fibrosis is a common chronic disease caused by long-term stimulation of one or more physical, chemical or microbial factors in the liver. Hepatic fibrosis is characterized by an aberrant accumulation of fibroblasts and excessive extracellular matrix (ECM) deposition, with evident inflammatory lesions and structural alterations (1). Despite the unclear pathogenesis of hepatic fibrosis, early diagnosis and treatment may reduce the mortality rate of patients (2). Therefore, attenuating or reversing hepatic fibrosis has become an important factor to be considered in the prevention and treatment of chronic hepatic injury and cirrhosis.

Hepatic stellate cells (HSCs) are the cells which primarily contribute to fibrogenesis during liver injury. These oval-shaped cells are located in the hepatic sinusoidal space and the space of Disse (3). Numerous retinoid lipid droplets may be observed in the cytoplasm of HSCs, indicating that the primary functions of HSCs are to store and metabolize vitamin A, secrete ECM and produce collagenase. Therefore, these cells are primarily involved in collagen synthesis in the liver. The activation and proliferation of HSCs are important events in hepatic fibrosis (4). A previous study suggested that the activation of HSCs may include three important stages: The initial stage, permanent stage and inflammation resolution stage (5). In the initial stage, ECM and other products, including peroxides, are released from the damaged hepatocytes. In the permanent stage, cellular behaviors are categorized into at least six types: Proliferation, chemotaxis, fibrogenesis, contraction, ECM degradation and vitamin A depletion. In the inflammation resolution stage, HSC apoptosis is promoted, or HSCs may be transformed into a quiescent state. Hepatocyte apoptosis and necrosis caused by various harmful factors, including the inflammatory response in liver tissues, activate Kupffer cells to secrete pro-inflammatory cytokines. These cytokines, in addition to various chemical transmitters, activate and transform HSCs into myofibroblasts, resulting in an alteration to the functional phenotype of HSCs (6). In addition, activated HSCs may promote the proliferation of myofibroblasts through paracrine or autocrine mechanisms, thereby synthesizing large amounts of collagen fibers and other ECM components. During this process, regulators, including tumor 
necrosis factor- $\alpha$ (TNF- $\alpha)(7,8)$, transforming growth factor $\beta 1$ (TGF- $\beta 1$ ) (9) and platelet-derived growth factor (PDGF) (10), and the ECM, interact with each other $(11,12)$ to form a sophisticated network and serve roles in hepatic fibrogenesis.

Among these cytokines, PDGF is the most potent factor involved in stimulating HSC proliferation, differentiation, and migration (10). PDGF additionally promotes collagen production and deposition, and transforms HSCs into myofibroblasts. Blocking PDGF signaling inhibits HSC proliferation and ameliorates liver fibrogenesis (12). Clinical studies have additionally confirmed that excessive activation of PDGF and its downstream molecules appears to be associated with the extent of necroinflammation and fibrosis in patients with hepatic damage (13-15). Therefore, the PDGF signaling pathway serves important roles in the development and prognosis of hepatic fibrosis.

\section{PDGF and the PDGF receptor (PDGFR)}

PDGF family. PDGF is a polypeptide growth factor with a relative molecular weight of 28-35 kDa; PDGF effectively promotes cell division and proliferation. PDGF is primarily produced by platelets, vascular endothelial cells, pericytes and Kupffer cells. PDGF, as the product of oncogenesis, was first identified in platelet $\alpha$-granules at 1,000 PDGF molecules/platelet. Under physiological conditions, PDGF is primarily secreted by Kupffer cells. Once a tissue has been damaged, various diploid cells may synthesize and secrete PDGF, which is associated with the proliferation of connective tissues, including fibroblasts, and vascular endothelial cells, via autocrine and paracrine mechanisms (16).

A total of four PDGF subunits, termed PDGF-A, -B, $-\mathrm{C}$ and $-\mathrm{D}$, have been identified. These subunits contain highly conservative homologous structural domains of PDGF/vascular endothelial growth factor (VEGF), and they produce five homologous or heterogeneous biopolymers, termed PDGF-AA, - BB, -AB, -CC, and -DD, via a disulfide-bond linkage $(17,18)$. Among the dipolymers, PDGF-A, which exhibits a molecular weight of $16 \mathrm{kDa}$, is composed of 211 amino acids (aa), and located at the chromosomal site 7p22. PDGF-A is highly-expressed in the muscle, aorta and heart (19). PDGF-B, with a molecular weight of $14 \mathrm{kDa}$, is located at the chromosomal site 22q13 and is highly-expressed in the placenta and heart. These two dipolymers are able to form three homologous or heterologous dipolymers, termed PDGF-AA, -BB and -AB. PDGF-AA primarily binds with PDGFR- $\alpha \alpha$ to control the proliferation and chemotaxis of cells, while PDGF-AB binds with PDGFR- $\alpha \alpha$ and PDGFR- $\alpha \beta$, and PDGF-BB binds with all subunits (PDGFR- $\alpha \alpha,-\alpha \beta$ and $-\beta \beta$ ); PDGFR-AB and -BB are able to promote collagen synthesis and cellular adhesion (17).

The remaining PDGF subunits, PDGF-C and PDGF-D, were discovered by comparing sequence data in the Expressed Sequence Tags database $(20,21)$. The structures and mechanisms of these subunits remain to be elucidated. PDGF-C is composed of $345 \mathrm{aa}$, exhibits a molecular weight of $36.7 \mathrm{kDa}$, and consists of three $\mathrm{N}$-linked glycosylation sites at the 22nd, 55th and 254th aa residues. PDGF-D consists of 370 aa, exhibits a molecular weight of $40.2 \mathrm{kDa}$, and consists of an $\mathrm{N}$-linked glycosylation site at its 276 th aa residue.
Unlike the first two isoforms, PDGF-C and PDGF-D only produce homologous biopolymers, termed PDGF-CC and PDGF-DD, the activity of which may be promoted via specific protease cleavage of their CUB domains. PDGF-C and -D are highly-expressed in the kidneys and heart.

PDGFR. PDGFR, which belongs to the receptor tyrosine kinase (RTK) family and serves the function of a protein tyrosine kinase, is primarily located in vascular endothelial cells, fibroblasts and Kupffer cells (22). PDGFs have two types of receptor, termed PDGFR- $\alpha$ and PDGFR- $\beta$, thereby forming three subtypes of dipolymers, termed PDGFR- $\alpha \alpha$, $-\alpha \beta$, and $-\beta \beta$. PDGFR- $\alpha$ and PDGFR- $\beta$ each contain five structural domains: Immunoglobulin-like domain, transmembrane domain, ATP binding site, intracellular hydrophilic kinase insert domain, and cytoplasmic tail; these receptors are respectively located at the chromosomal sites $4 \mathrm{q} 12$ and $5 \mathrm{q} 33$. PDGFR- $\alpha$ and PDGFR- $\beta$ display different expression patterns and physiological functions. Additionally, the PDGFR- $\alpha$ signal and the PDGF-A, PDGF-B and PDGF-C chains, which exhibit close binding affinities, are associated with the early hematopoietic system and vascularization (23); however, PDGF-B and PDGF-D exhibit high binding tendencies with PDGFR- $\beta$ (24). Therefore, PDGF-B is more sensitive to PDGFR- $\alpha$ and PDGFR- $\beta$ compared with other subunits.

\section{Biological functions of PDGF and PDGFR}

In physiological conditions, PDGF is primarily expressed in the $\alpha$-granules of platelets. However, when liver damage occurs, PDGF may be highly-expressed in macrophages, injured endothelial cells and activated HSCs. During the early stages of various chronic liver diseases, increased PDGFR expression on the membranes of activated HSCs, in addition to activation of HSCs by the synthesized PDGF via the autocrine mechanism, enhances cellular chemotaxis and decreases the amount of intracellular vitamin A, demonstrating that PDGF is involved in ECM production $(22,23)$. Further studies have also demonstrated that the four PDGF subunits serve different roles in the pathogenesis of hepatic fibrosis. In particular, PDGF-B has been demonstrated to be the most potent factor associated with HSC activation $(23,25)$. PDGF-A mRNA expression exhibits a minor fluctuation during the process of activated HSC transdifferentiation to myofibroblast-like cells; PDGF-B is elevated during the early stage, although it is markedly reduced from day 3 (17). By contrast, PDGF-C and -D mRNA levels continuously rise during the whole process of transdifferentiation (17). In addition, quiescent HSCs only express PDGFR- $\alpha$, whereas activated HSCs display a marked upregulation of the expression of PDGFR. The expression profile of PDGFR- $\beta$ mRNA is consistent with that of PDGF-C and -D during transdifferentiation (17). This finding indicated that signal transduction is primarily mediated by PDGF-B at the early stage, and by PDGF-C and PDGF-D at the late stage of hepatic fibrogenesis (17).

A previous study demonstrated that the PDGFR- $\beta$-mediated PDGF-B and PDGF-D signaling pathways are the most important proliferation signaling pathways in the development of hepatic fibrosis (26). In a rat model of fibrotic liver disease induced by bile duct ligation (BDL), the expression of 


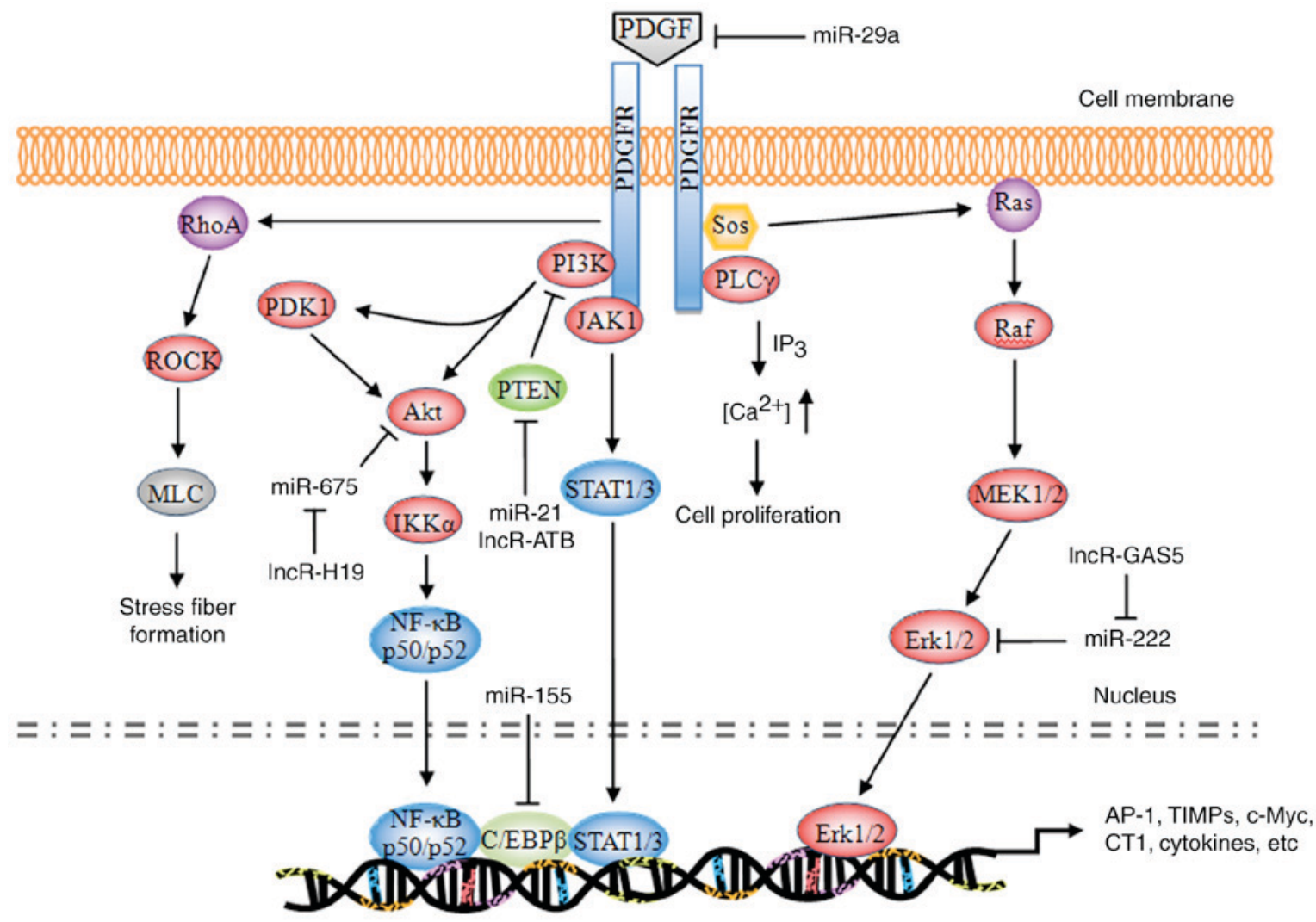

Figure 1. Schematic representation of the PDGF signaling pathway. PDGF, platelet-derived growth factor; PDGFR, PDGF receptor; miR, microRNA; PI3K, phosphatidylinositol 3-kinase; PLC $\gamma$, phospholipase $\mathrm{C} \gamma$; Sos, son of sevenless homolog; JAK1, tyrosine-protein kinase JAK1; PDK1, 3-phosphoinositide-dependent protein kinase 1; Akt, RAC- $\alpha$ serine/threonine protein kinase; PTEN, phosphatidylinositol 3,4,5-trisphosphate 3-phosphatase and dual-specificity protein

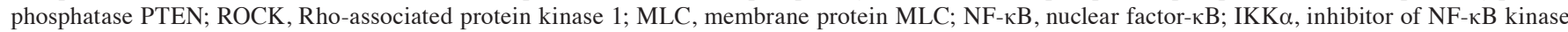
subunit $\alpha ; \mathrm{C} / \mathrm{EBP} \beta, \mathrm{CCAAT/enhancer-binding} \mathrm{protein} \beta ;$ STAT, signal transducer and activator of transcription; MEK, dual specificity mitogen-activated protein kinase kinase; Erk, extracellular signal-regulated kinase; AP-1, transcription factor AP-1; TIMP, metalloproteinase inhibitor; c-Myc, myc proto-oncogene protein; CT1, cardiotrophin 1.

PDGF-B, PDGF-D, and PDGFR- $\beta$ mRNA were respectively increased compared with the other isotypes; PDGF-B- and PDGF-D-stimulated HSC activation and proliferation markedly altered, exhibiting apparent activation morphologically. By contrast, the proliferation of cells treated with PDGF-A or PDGF-C did not alter (27). This previous result indicated that PDGF-B and -D may induce more apparent hepatic fibrosis compared with PDGF-A and -C. In addition, hepatic fibrosis and HSC activation have been demonstrated to be markedly increased in transgenic mice overexpressing PDGF-BB compared with normal controls; the expression levels of $\alpha$-smooth muscle actin ( $\alpha$-SMA) and PDGFR- $\beta$ in the liver were also elevated, demonstrating that PDGF-B and PDGFR- $\beta$ may promote fibrosis in an animal model and at the cellular level (28). Therefore, PDGFR- $\beta$ expression may be most apparent in the cytomembranes of HSCs. PDGFR- $\beta$ may additionally exhibit relatively strong affinities with PDGF-B and -D, and these three factors serve important roles in hepatic fibrosis.

\section{PDGF signaling pathway}

The majority of the substrates of PDGF exhibit similar structures to the Src homology 2 (SH2) domain. These substrates bind to a corresponding phosphorylation site of the activated PDGFR, enabling receptor dimerization and autophosphorylation, and leading to phosphorylation of tyrosine residues at specific intracellular sites (29). The currently identified substrates primarily include phospholipase $\mathrm{C} \gamma$ (PLC $\gamma)$, Ras, phosphatidylinositol 3-kinase (PI3K), and the signal transducer and activator of transcription (STAT) pathway (Fig. 1).

During the development of hepatic fibrosis, autophosphorylated PDGFR primarily activates the Ras system, which in turn activates the RAF proto-oncogene serine/threonine protein kinase (Raf-1), dual-specificity mitogen-activated protein kinase kinaseN (MEK) and extracellular signal-regulated protein kinase (ERK) signaling pathways. The activated signaling pathways enhance the phosphorylation of cytoplasmic target proteins, regulate the activity of various proteases, promote the phosphorylation of a number of transcription factors [including activator protein 1 (AP-1) and nuclear factor $-\kappa \mathrm{B}(\mathrm{NF}-\kappa \mathrm{B})]$ and enable them to bond with the target gene promoters of the corresponding response elements. Consequently, these downstream elements increase the transcriptional activity, regulate the expression levels of the products of target genes [including type I collagen (CT I), metalloproteinase inhibitors (TIMPs), matrix metalloproteinases (MMPs), apoptosis regulator Bcl-2 (Bcl-2), and E3 ubiquitin-protein ligase XIAP (XIAP)], resulting in cell division, proliferation and apoptosis (30-32).

Ras pathway. Ras is a small GTPase with a relative molecular weight of $21 \mathrm{kDa}$. Ras has been demonstrated to be a 'crossing 
point' or molecular switch for a variety of cell signal transduction processes. The protein possesses endogenous GTP enzyme activity, facilitating extracellular-to-intracellular signaling, and is additionally an upstream protein of the Raf-MEK-ERK pathway (33). Ras, combined with c-Raf-1, facilitates the transport of Raf from the cytoplasm to the cytomembrane; Raf is subsequently activated by the corresponding kinase on the cytomembrane and its C-end catalytic domain bonded with MEK phosphorylates (via MAPK) two Ser residues in the MEK catalytic domain, thereby activating MEK.

PDGF, combined with a corresponding receptor on the cytomembrane, induces the phosphorylation of intracellular tyrosine residues of the receptor; the phosphorylated tyrosine may recruit GF receptors containing SH structural domains from the cytoplasm to bond with the protein 2 (Grb2); by virtue of its SH2 structural domain, Grb2 binds with the guanine nucleotide exchange factor [son of sevenless (SOS)] and forms a Grb2-SOS compound, which dissociates the GDP of Ras to bind with GTP and converts the quiescent Ras-GDP into an active Ras-GTP to activate Ras. The activated Ras in turn activates Raf1, MEK1/2 and ERK1/2 and transfers the corresponding signals into the cell nucleus, thereby promoting the phosphorylation of various transcription factors, increasing transcriptional activity, and triggering cell growth, differentiation, migration, angiogenesis, anti-apoptosis, drug tolerance and other processes $(34,35)$. During the induction of hepatic fibrosis by PDGF, ERK1/2 primarily regulates the mitosis and chemotaxis of HSCs. The ERK1/2 pathway inhibitor is able to completely inhibit mitosis in HSCs and decrease the mitogenesis and chemotaxis of the cells, thus reducing the concentration of inflammatory sites (36-38).

$P L C \gamma$ pathway. PLC $\gamma$ is a $145-\mathrm{kDa}$ enzyme consisting of two SH2 domains and one SH3 domain. In hepatic fibrosis, PDGF mediates the cell proliferation via the regulatory role of PLC $\gamma$ in the mitosis of HSCs (39). The primary mechanism of action is as follows: When PDGF is bonded with PDGFR, PLC $\gamma$ is activated by a protein tyrosine kinase; the activated PLC $\gamma$ hydrolyzes phosphatidylinositol diphosphate, producing inositol triphosphate (IP3) and diacylglycerol (DAG). IP3 primarily acts on the $\mathrm{Ca}^{2+}$ repository of the endoplasmic reticulum, promoting the release of cytoplasmic $\mathrm{Ca}^{2+}$; the intracellular $\mathrm{Ca}^{2+}$ thus increases and induces mitosis in HSCs. DAG, together with $\mathrm{Ca}^{2+}$, acts on the protease protein kinase $\mathrm{C}(\mathrm{PKC})$ and induces the phosphorylation of Ser and Thr residues of the ribosome, in addition to the proliferation of cells $(40,41)$. In addition, DAG is able to activate the intracellular $\mathrm{Na}^{+} / \mathrm{H}^{+}$proton pump, leading to the frequent intracellular $\mathrm{H}^{+}$and extracellular $\mathrm{Na}^{+}$interchanges; DAG additionally decreases the quantity of cellular $\mathrm{H}^{+}$, which is conducive to mitosis $(42,43)$.

PI3K pathway. PI3K is a heterogeneous dipolymer consisting of two subunits, termed p85 and p110. p85 is the subunit which regulates the primary functions of PI3K (44). The RAC- $\alpha$ serine/threonine protein kinase (Akt/PKB) pathway is currently considered to be the primary downstream signaling pathway of PI3K. PKB is a serine/threonine protease and it encompasses three domains: The $\mathrm{N}$-terminal regulatory domain, the catalytic domain, and the $\mathrm{C}$-terminal tail domain. The specific signaling pathway is as follows: The p85 subunit, which is bonded with the phosphorylated PDGFR, phosphorylates the third group of the phosphatidylinositol ring, producing PI $(3,4)$ P2, PI (3-5) P3, and certain secondary messengers for downstream signaling; the latter may bind with the group via the $\mathrm{N}$-terminal regulatory domain of $\mathrm{PKB}$, transporting it to the cytomembrane or partially activating it. Notably, phosphorylated sites respectively activate 3-phosphoinositide-dependent protein kinase 1 (PDK1) and PDK2; subsequently, PDK1 and PDK2, or an unknown Ser473 kinase, phosphorylates the Ser473 and Thr308 ion of the PKB protein, thereby completely activating the group. The PDGFR-activated PI3K/Akt pathway may promote actin recombination, increase cell migration, mediate metabolic regulation, stimulate cell growth and inhibit cellular apoptosis (45). ERK signaling is involved in PI3K/Akt-mediated HSC chemotaxis and proliferation (46).

Tyrosine protein kinase JAK (JAK)/STAT pathway. STAT signaling is a process wherein an $84-113-\mathrm{kDa}$ cytoplasmic protein, combined with the regulatory domain DNA of the target gene, regulates transcription. A total of seven STAT family members have been identified, termed STATI, STAT2, STAT3, STAT4, STAT5a, STAT5b, and STAT6. STAT is an intracellular signal transduction protein, and additionally acts as a transcription factor (47). Following phosphorylation by tyrosine protein kinases of the JAK family, STATs produce homologous or heterogeneous dipolymers; the dipolymers are subsequently translocated, enter the nucleus, and trigger gene transcription following DNA-binding (48). Activated PDGFR primarily triggers the phosphorylation of the C-terminal tyrosine residues (Tyr705) and serine residues (Ser727) of the STAT protein via JAKs, thereby activating STAT5, leading to the production of homologous or heterologous STAT protein dipolymers. The dipolymers are subsequently translocated, enter the nucleus, activate the target genes, and promote cell growth and division $(49,50)$.

Rho pathway. Using two intracellular signaling pathways (PKC and RhoA), PDGF alters the cytoskeleton distribution in HSCs, stimulates the transformation of HSCs into muscle-like fibroblasts, and promotes type I and III collagen formation (51).

Non-coding RNA (ncRNA) regulation. Altered profiles of ncRNAs, including microRNAs (miRNAs/miRs), long non-coding RNAs (IncRNAs) and circular RNAs (circRNAs), have been demonstrated to be associated with hepatic fibrosis. Different alterations of miRNA expression have been observed. Several specific miRNAs (including let-7d, miR-29a, miR-21, miR-155 and miR-214) (52-56) and lncRNAs (lncRNA-ATB, GAS5 and H19) (57-59), have been identified to be diagnostic biomarkers and the therapeutic targets in the progression of hepatic fibrosis. miRNAs induced or repressed by PDGF challenge exhibit a feedback mechanism balancing multiple growth factor receptor signaling in HSC activation $(52-56,60,61)$, while lncRNAs are able to competitively bind to anti-fibrogenic miRNAs leading to increased collagen I production (57-59). Since a single ncRNA may affect the expression of various mRNAs, it may simultaneously modulate various cellular events. At present, the multiple molecular mechanism through which ncRNAs may serve a role in hepatic fibrogenesis have not been completely elucidated. 


\section{Targeting the PDGF signaling pathway in hepatic fibrosis treatment}

With the increased understanding of the biological functions of the PDGF signaling pathway in liver fibrogenesis, antifibrotic drugs have become a focus of research. A number of strategies to regulate the PDGF signaling pathway have been employed in preclinical and clinical settings (Table I). These may be categorized as: i) PDGF isoform antagonists; ii) blocking of PDGFR activation; and iii) downstream regulation of the PDGF pathway.

PDGF-B kinoid vaccines, prepared using PDGF-B-derived polypeptides bonded to carrier protein heterocomplexes, displayed marked antifibrotic effects in $\mathrm{CCl}_{4}$-induced hepatic fibrosis (62). Notably, the normal function of the hepatocytes was not altered by the vaccine. Although the side effects were not observed in this previous study and in other reports (63-65), the safety of PDGF vaccine requires investigation in a systematic toxicity assay.

Sorafenib is a first-line oral chemotherapy drug for patients with advanced hepatocellular carcinoma. As an RTK inhibitor, sorafenib may target a number of kinases on the cytomembrane, including Raf, VEGFR2/3, and PDGFR- $\beta(66,67)$. Despite the narrow therapeutic window and adverse effects $(68,69)$, sorafenib has previously been demonstrated to be a potential antifibrotic agent, due to its multi-targeting of the Ras/MEK/ERK pathway (70). Sorafenib may induce HSC autophagy and apoptosis through activation of the Akt/protein kinase mTOR/p70S6K and MAPK signaling pathways (71). It may additionally suppress collagen deposition, neovascularization and oxidative stress through PDGF downregulation, STAT3 inhibition and mitochondrial respiration in fibrosis mouse models consuming a high fat diet, and undergoing BDL and dimethylnitrosamine injection $(72,73)$.

Nilotinib, a selective breakpoint cluster region protein (Bcr)-tyrosine-protein kinase ABL (Abl) non-receptor tyrosine kinase (nRTK) inhibitor, is well-tolerated and has been approved for the treatment of leukemia. Since RTKs may be activated by nRTKs, the interaction between RTKs and nRTKs is involved in the regulation of HSC differentiation and proliferation (74). In addition to its anticancer activity, nilotinib therefore exerts numerous beneficial therapeutic outcomes, including neuroprotective, vasodilatory and antifibrotic effects (75-78). Nilotinib inhibited $\alpha$-SMA, procollagen-(I), TIMP-1, phosphorylated (p)-ERK and p-Akt expression, and reduced collagen deposition in activated HSCs and in the liver tissues of $\mathrm{CCl}_{4}$ - and BDL-induced fibrosis rats (79-81). Nilotinib inhibited PDGFR activation, in addition to TGF $\beta$ receptor type II via Src (81). These previous results indicated that nilotinib may represent a putative antifibrotic treatment due to its combined inhibition of nRTK and RTK.

Imatinib (also termed Gleevec ${ }^{\circledR}$ and STI-571) is a selective tyrosine kinase inhibitor (TKI), which is able to specifically target PDGFR, Abl, Abelson tyrosine-protein kinase 2, mast/stem cell growth factor receptor, and their oncogenic forms Bcr-Abl (82). At concentrations required for Bcr-Abl inhibition, imatinib is additionally able to attenuate hepatic fibrosis by blocking the expression of PDGFR- $\beta$ and decreasing the levels of proinflammatory cytokines. Therefore, imatinib has been demonstrated to induce HSC apoptosis in vitro and to control liver fibrosis in $\mathrm{CCl}_{4}$ - and thioacetamide (TAA)-treated mice (80,82-84). Compared with a decreased of $60 \%$ mediated by anti-PDGF antibodies, imatinib has been demonstrated to exert an $85 \%$ decrease in HSC migration triggered by bile duct segments (27). However, unlike nilotinib, animals treated with imatinib $(20 \mathrm{mg} / \mathrm{kg})$ exhibited a degree of hepatotoxicity evidenced by increased levels of serum aminotransferases and total bilirubin (79).

Other TKIs, including pazopanib, regorafenib, AG1295 and AG1296, may selectively inhibit the tyrosine phosphorylation of PDGFR- $\beta$ (85-87) and the PDGF-BB-induced activation of its downstream signaling pathway in HSCs (85). additionally, AG1295 inhibits PDGF-induced thymidine uptake by pulmonary myofibroblasts in vitro (88).

Celecoxib, etoricoxib and DFU, selective cyclooxygenase-2 (COX-2) inhibitors (coxibs), are widely-used in the management of osteoarthritis and rheumatoid arthritis, in addition to the treatment of colon cancer, atherosclerosis and Alzheimer's disease, due to their analgesic, anticoagulant and anti-inflammatory effects (89-91). During the development of steatohepatitis and hepatic fibrosis, COX-2 and its products prostaglandin $\mathrm{E}_{2}\left(\mathrm{PGE}_{2}\right)$ and prostacyclin (PGI) may upregulate the expression of VEGF, PDGF and fibroblast growth factor receptor 1, resulting in ERK activation, and COX-2 may be activated by these factors (92). COX-2 inhibitors may alter the metabolism of arachidonic acid and, subsequently, $\mathrm{PGE}_{2}$ and PGI. Therefore, coxibs may inhibit PDGF-induced HSC proliferation; however, in contrast to NS-398 and DFU, only celecoxib $(\geq 50 \mathrm{mM})$ is able to induce HSC apoptosis and inhibit Akt activation (93). Oral administration of celecoxib significantly decreased hepatic collagen deposition and $\alpha$-SMA expression in $\mathrm{CCl}_{4}$ - and TAA-treated rats due to its dual inhibitory effects on intrahepatic fibrosis and angiogenesis (94).

A number of active substances from traditional herbal and ethnobotanical medicine [e.g., silymarin, quercetin, proanthocyanidins, curcumin and salvianolic acid B (Sal B)] have come into use as putative treatments for liver disease. Silymarin, a mixture of flavonolignans obtained from the edible milk thistle plant [Silybum marinaum (L) Gaenrt], has been used as a natural medicine for the treatment of liver diseases. The four principal isomers within silymarin are silybin, isosilybin, siliehristin and silydianin (95). Among these isomers, silybin is the most bioactive substance, which is able to directly inhibit the phosphorylation of the Raf/MEK/ERK pathway, decrease the activation of sodium/hydrogen exchanger 1 and inhibitor of $\mathrm{NF}-\kappa \mathrm{B} \alpha$ phosphorylation, thereby preventing oxidative anomalies and fibrosis $(96,97)$. Treatment with silybin or silybin-vitamin E phospholipid complexes has been demonstrated to ameliorate hepatic fibrosis in patients with chronic hepatitis $\mathrm{C}$, who have been treated previously with pegylated-interferon a and ribavirin $(98,99)$.

Curcumin, the principal component of the spice turmeric and certain herbal medicines (Zedoariae rhizome and Radix Curcumae), is able to inhibit epithelial-to-mesenchymal transition and affect numerous intracellular targets, involving certain miRNAs, and the estrogen receptor, nuclear factor-like 2, insulin-like growth factor-1 and PI3K/Akt signaling pathways (100-103). Due to its numerous potential effects, including anti-inflammatory, hypolipidemic, hypoglycemic and chemopreventive activity, curcumin may increase antioxidant enzyme activities, activate cytochrome P4502E1 and concomitantly 


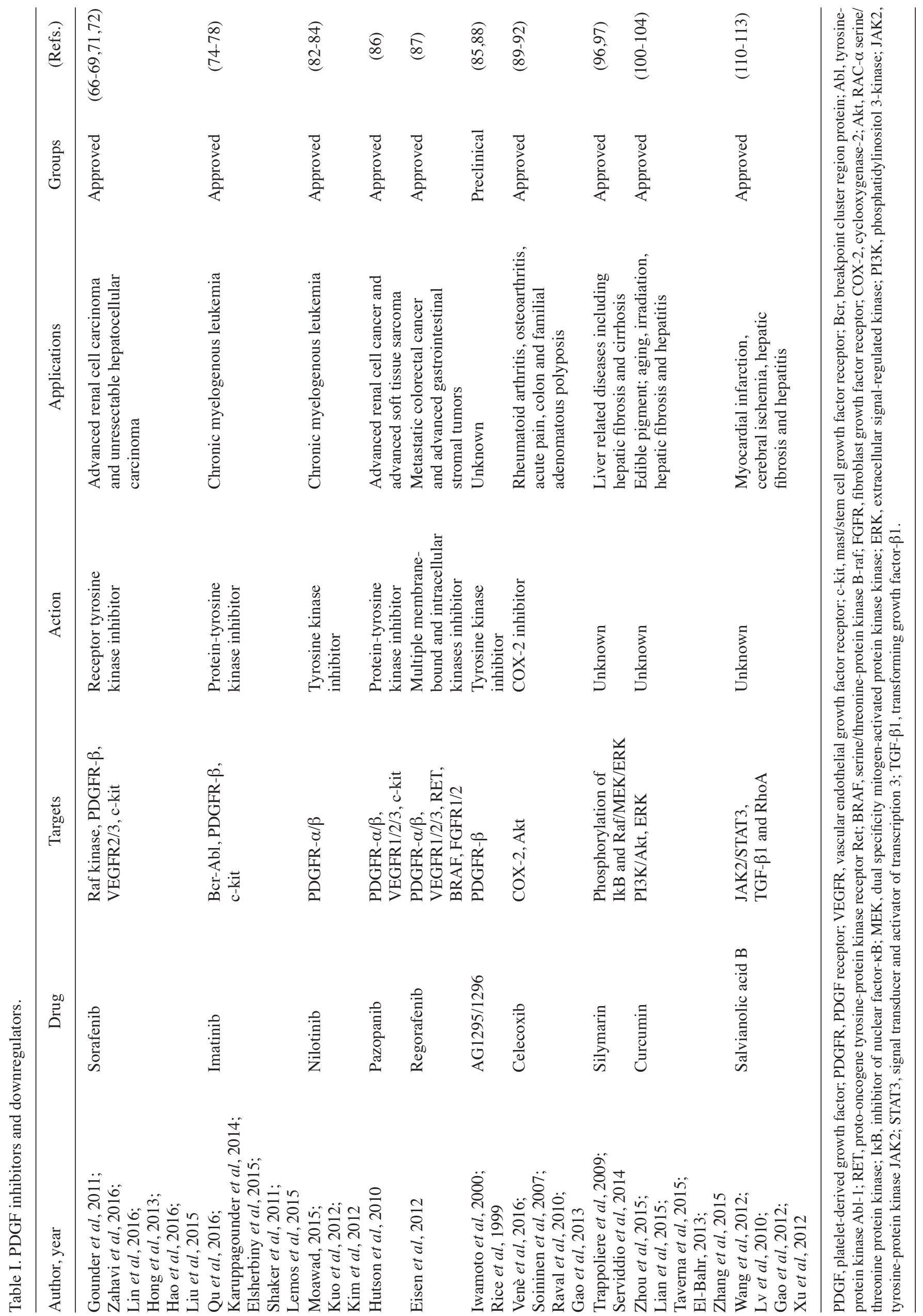




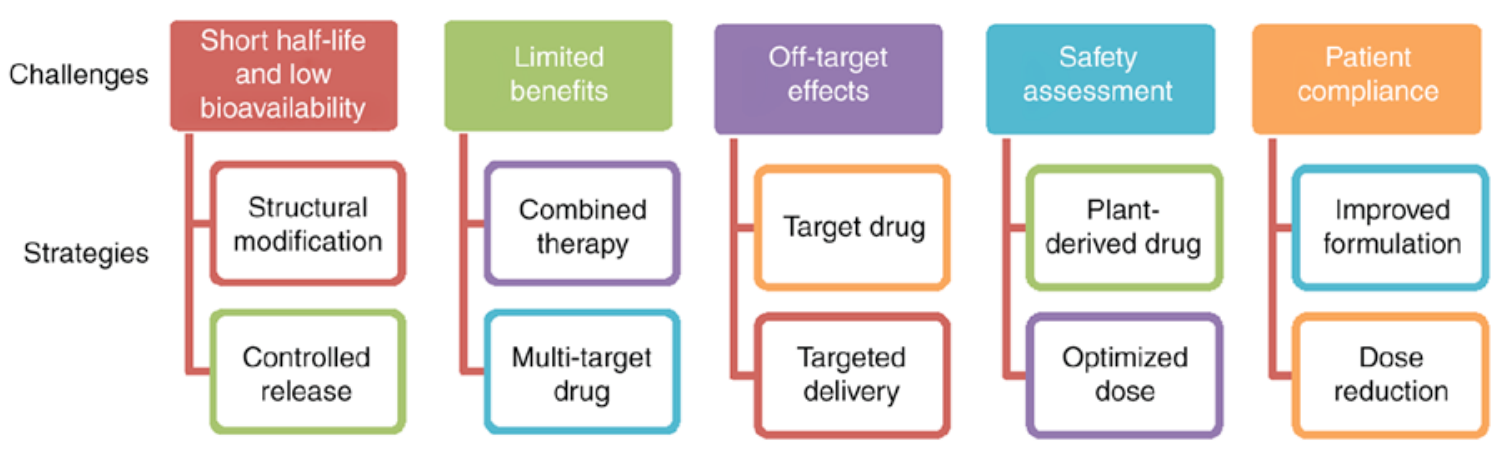

Figure 2. Recent challenges and future strategies for the treatment of hepatic fibrosis.

suppress the activity of fatty acid synthase, $\beta$-catenin transactivation and DNA-binding $(104,105)$. In addition, curcumin has been demonstrated to markedly reverse PDGF-BB-induced hepatic myofibroblast cell proliferation and the expression of collagen I and collagen IV mRNA. Curcumin may alleviate hepatic fibrosis by modulating lipid metabolism and inducing HSC apoptosis, in part via the PDGF- and ERK-dependent pathway $(101,106)$.

Sal B, and its metabolite danshensu, the major active substances from Salvia miltiorrhiza, are widely-used as commercial anticoagulant drugs in the treatment of myocardial infarction and cerebral ischemia (107-109). The two substances exhibit hepatoprotective effects against $\mathrm{CCl}_{4}$-induced lipid peroxidation, collagen accumulation and necroinflammation in liver tissues, the probable mechanism underlying which is associated with the regulation of the intrahepatic JAK2/STAT3 and TGF- $\beta 1 /$ mothers against decapentaplegic homolog pathways for maintaining collagenic homoeostasis (110-112). In vitro, Sal B has been demonstrated to inhibit endothelin-induced HSC activation by regulating RhoA/cardiac myosin light chain 2 signaling activation and the phosphorylation of downstream protein phosphatase 1 regulatory subunit $12 \mathrm{~A}$ at $\operatorname{Thr}(696)$ (113).

\section{Future challenges and prospects}

PDGF-B-mediated PDGFR- $\beta$ signaling has been demonstrated to serve an important role in hepatic fibrosis $(17,22)$. Although the numerous approaches mentioned above have been applied to modulate this pathway, no ideal treatment for liver fibrosis has been employed in clinical practice at present (Fig. 2). TKIs, coxibs and natural products exhibit short half-lives and low bioavailabilities, and therefore require long-time repeated administration to achieve therapeutic benefits $(114,115)$. In addition, the majority of TKIs are only approved for cancer therapy, and coxibs for arthritis. Although the effectiveness of TKIs and coxibs has been demonstrated in animal models and cultured HSCs, the outcomes of patients treated in early-phase clinical trials have not been systematically analyzed. Notably, due to the high similarity of the homologous domain, TKIs, including sorafenib, sunitinib and pazopanib, may inhibit PDGFR expression and regulate the expression of VEGF receptors (VEGFR), which are involved in the maintenance of vessel diameters and the integrity of endothelial cells (116); therefore, the inhibition of PDGFR by these approved targeted drugs may impair non-target normal cells or tissues. The primary concerns about the safety of TKIs and coxibs are bleeding and myocardial ischemia. Congestive liver failure, QT prolongation and severe fatigue induced by TKIs have additionally been observed in certain clinical trials (117-119). With the development of molecular biotechnology methods, gene therapy may be used to transport genetic materials to the specific cells for correcting or targeting the genetic defects, thereby achieving the goal of disease treatment. However, there are significant potential safety and target-specific concerns associated with small interfering RNA- and adenovirus-mediated gene therapies involving genetic modification (120).

An additional challenge is that the inhibition of a single profibrotic molecule may exert little or no impact on fibrogenesis and overall recovery. Hepatic fibrogenesis is a complex process involving a variety of pathogenic and host-specific signal transduction processes (4). Certain stimuli, including TGF- $\beta 1$, TNF- $\alpha$ and hepatitis viruses, serve roles in HSC activation. Different stages of fibrosis development may depend on different growth factors (7-9). Notably, PDGF mediates the actions of these stimuli in liver cells, including the regulation of hepatocyte growth and death, in addition to the differentiation of activated HSCs to myofibroblasts; conversely, TGF- $\beta 1$, TNF- $\alpha$ and hepatitis-mediated oxidative stress may upregulate PDGF expression $(121,122)$. In particular, hepatitis B virus- or hepatitis $\mathrm{C}$ virus-associated fibrosis is considered to be irreversible prior to the control of the ongoing viral replication and inflammation by combined treatment (123). In addition, it remains unknown whether the normal biological functions of the liver may be affected by the inhibition of PDGF signaling. Considering that that liver is a non-immunological organ engaged primarily in metabolism, nutrient storage and detoxification, novel therapies are required to deliver longer lasting benefits directly to the targeted cells. Combination strategies (including multi-agent regimens and improved drug delivery) are the future of antifibrotic therapy, and the primary focus for medicinal chemistry is the reduction of toxicity and the maintenance (or enhancement) of potency. Novel combinations may simultaneously target multiple profibrotic factors to induce HSC apoptosis, improve the microenvironment, prolong drug release and reverse drug resistance. Co-delivery systems modified by nanotechnology may be a promising strategy to maximize the additive or synergistic effects of drugs, since various agents may specifically bind to the target together. These multi-target delivery systems, which may more specifically deliver inhibitors to the target, may be able to increase the antifibrotic action and decrease the exposure of 
normal and non-targeted cells or tissues. However, epidemiological evidence for the association between plant remedies (involving the mixed herbal formulations) and the long latency of hepatic fibrosis progression has led to the active investigation of natural chemicals from different naturally-occurring substances in various preclinical and clinical studies. In general, the potential of natural compounds to exhibit low toxicity and low drug-resistance, with pleiotropy and synergistic action, makes them promising candidates for the treatment of hepatic fibrosis. A number of plant-derived active compounds have been approved for the treatment of hepatic fibrosis and may provide valuable resources for the development of novel formulations and treatment modalities in future.

\section{Conclusion}

In conclusion, excessive PDGF expression is an important factor in HSC activation. Hepatic fibrosis may be effectively reversed by inhibiting PDGF and PDGFR expression, or by inhibiting the phosphorylation of its downstream signaling pathways, although complete elucidation of the mechanisms underlying signaling transduction and crosstalk between the different pathways requires additional research. A number of PDGF antagonists and receptor inhibitors have been previously investigated for their potential to treat hepatic fibrosis, although further clinical trials to examine their safety and effectiveness may be considered.

\section{Acknowledgements}

The present study was funded by the National Natural Science Foundation of China (grant no. 81573591), the Zhejiang Science and Technology Foundation (grant nos. 2014F10033 and 2015F50056), Zhejiang Innovation discipline 'Laboratory Animal Genetic Engineering' (grant no. 201604) and the Zhejiang Foundation for the Cultivation of High-level Innovative Health Talents (grant no. 201206).

\section{References}

1. Bonder A, Tapper EB and Afdhal NH: Contemporary assessment of hepatic fibrosis. Clin Liver Dis 19: 123-134, 2015.

2. Trautwein C, Friedman SL, Schuppan D and Pinzani M: Hepatic fibrosis: Concept to treatment. J Hepatol 62 (1 Suppl) S15-S24, 2015.

3. Jacobs F, Wisse E and De Geest B: The role of liver sinusoidal cells in hepatocyte-directed gene transfer. Am J Pathol 176 14-21, 2010.

4. Tacke F and Weiskirchen R: Update on hepatic stellate cells: Pathogenic role in liver fibrosis and novel isolation techniques. Expert Rev Gastroenterol Hepatol 6: 67-80, 2012.

5. Yin C, Evason KJ, Asahina K and Stainier DY: Hepatic stellate cells in liver development, regeneration, and cancer. J Clin Invest 123: 1902-1910, 2013.

6. Liu W, Baker RD, Bhatia T, Zhu L and Baker SS: Pathogenesis of nonalcoholic steatohepatitis. Cell Mol Life Sci 73: 1969-1987, 2016.

7. Robert S, Gicquel T, Bodin A, Lagente V and Boichot E: Characterization of the MMP/TIMP imbalance and collagen production induced by IL-1 $\beta$ or TNF- $\alpha$ release from human hepatic stellate cells. PLoS One 11: e0153118, 2016.

8. Ceccarelli S, Panera N, Mina M, Gnani D, De Stefanis C, Crudele A, Rychlicki C, Petrini S, Bruscalupi G, Agostinelli L, et al: LPS-induced TNF- $\alpha$ factor mediates pro-inflammatory and pro-fibrogenic pattern in non-alcoholic fatty liver disease. Oncotarget 6: 41434-41452, 2015.
9. Shah R, Reyes-Gordillo K, Arellanes-Robledo J, Lechuga CG, Hernández-Nazara Z, Cotty A, Rojkind M and Lakshman MR: TGF- $\beta 1$ up-regulates the expression of PDGF- $\beta$ receptor mRNA and induces a delayed PI3K-, AKT- and p70(S6K)-dependent proliferative response in activated hepatic stellate cells. Alcohol Clin Exp Res 37: 1838-1848, 2013.

10. Kocabayoglu P, Lade A, Lee YA, Dragomir AC, Sun X, Fiel MI, Thung S, Aloman C, Soriano P, Hoshida Y and Friedman SL: $\beta$-PDGF receptor expressed by hepatic stellate cells regulates fibrosis in murine liver injury, but not carcinogenesis. J Hepatol 63: 141-147, 2015.

11. Baig MS, Yaqoob U, Cao S, Saqib U and Shah VH: Non-canonical role of matrix metalloprotease (MMP) in activation and migration of hepatic stellate cells (HSCs). Life Sci 155: 155-160, 2016.

12. Tang N, Zhang YP, Ying W and Yao XX: Interleukin-1 $\beta$ upregulates matrix metalloproteinase-13 gene expression via c-Jun $\mathrm{N}$-terminal kinase and p38 MAPK pathways in rat hepatic stellate cells. Mol Med Rep 8: 1861-1865, 2013.

13. Jain MK, Adams-Huet B, Terekhova D, Kushner LE, Bedimo R, Li X and Holodniy M: Acute and chronic immune biomarker changes during interferon/ribavirin treatment in $\mathrm{HIV} / \mathrm{HCV}$ co-infected patients. J Viral Hepat 22: 25-36, 2015.

14. Bai Q, An J, Wu X, You H, Ma H, Liu T, Gao N and Jia J: HBV promotes the proliferation of hepatic stellate cells via the PDGF-B/PDGFR- $\beta$ signaling pathway in vitro. Int J Mol Med 30: 1443-1450, 2012.

15. Okada H, Honda M, Campbell JS, Sakai Y, Yamashita T, Takebuchi Y, Hada K, Shirasaki T, Takabatake R, Nakamura M, et al: Acyclic retinoid targets platelet-derived growth factor signaling in the prevention of hepatic fibrosis and hepatocellular carcinoma development. Cancer Res 72: 4459-4471, 2012.

16. Friedman SL, Wei S and Blaner WS: Retinol release by activated rat hepatic lipocytes: Regulation by Kupffer cell-conditioned medium and PDGF. Am J Physiol 264: G947-G952, 1993.

17. Breitkopf K, Roeyen Cv, Sawitza I, Wickert L, Floege J and Gressner AM: Expression patterns of PDGF-A,-B, -C and -D and the PDGF-receptors alpha and beta in activated rat hepatic stellate cells (HSC). Cytokine 31: 349-357, 2005.

18. Fredriksson L, Li H and Eriksson U: The PDGF family: Four gene products from five dimeric isoforms. Cytokine Growth Factor Rev 15: 197-204, 2004.

19. Sarzani R, Arnaldi G and Chobanian AV: Hypertension-induced changes of platelet-derived growth factor receptor expression in rat aorta and heart. Hypertension 17: 888-985, 1991.

20. Bergsten E, Uutela M, Li X, Pietras K, Ostman A, Heldin CH, Alitalo $\mathrm{K}$ and Eriksson U: PDGF-D is a specific, protease-activated ligand for the PDGF beta-receptor. Nat Cell Biol 3: 512-516, 2001.

21. Uutela M, Laurén J, Bergsten E, Li X, Horelli-Kuitunen N, Eriksson U and Alitalo K: Chromosomal location, exon structure, and vascular expression patterns of the human PDGFC and PDGFD genes. Circulation 103: 2242-2247, 2001.

22. Liegl B, Leithner A, Bauernhofer T, Windhager R, Guelly C, Regauer $\mathrm{S}$ and Beham A: Immunohistochemical and mutational analysis of PDGF and PDGFR in desmoid tumours: Is there a role for tyrosine kinase inhibitors in c-kit-negative desmoid tumours? Histopathology 49: 576-581, 2006.

23. Rosenfeld M, Keating A, Bowen-Pope DF, Singer JW and Ross R: Responsiveness of the in vitro hematopoietic microenvironment to platelet-derived growth factor. Leuk Res 9: 427-434, 1985.

24. Ogawa S, Ochi T, Shimada H, Inagaki K, Fujita I, Nii A, Moffat MA, Katragadda M, Violand BN, Arch RH and Masferrer JL: Anti-PDGF-B monoclonal antibody reduces liver fibrosis development. Hepatol Res 40: 1128-1141, 2010.

25. Park HJ,Kim HG, Wang JH, Choi MK, Han JM, Lee JS and Son CG: Comparison of TGF- $\beta$, PDGF, and CTGF in hepatic fibrosis models using DMN, $\mathrm{CCl}_{4}$ and TAA. Drug Chem Toxicol 39: 111-118, 2016.

26. Borkham-Kamphorst E, Meurer SK, Van de Leur E, Haas U, Tihaa L and Weiskirchen R: PDGF-D signaling in portal myofibroblasts and hepatic stellate cells proves identical to PDGF-B via both PDGF receptor type $\alpha$ and $\beta$. Cell Signal 27: 1305-1314, 2015.

27. Kinnman N, Hultcrantz R, Barbu V, Rey C, Wendum D, Poupon R and Housset C: PDGF-mediated chemoattraction of hepatic stellate cells by bile duct segments in cholestatic liver injury. Lab Invest 80: 697-707, 2000.

28. Czochra P, Klopcic B, Meyer E, Herkel J, Garcia-Lazaro JF, Thieringer F, Schirmacher P, Biesterfeld S, Galle PR, Lohse AW and Kanzler S: Liver fibrosis induced by hepatic overexpression of PDGF-B in transgenic mice. J Hepatol 45: 419-428, 2006. 
29. Twamley-Stein GM,Pepperkok R, Ansorge W and Courtneidge SA The Src family tyrosine kinases are required for platelet-derived growth factor-mediated signal transduction in NIH 3 T3 cells. Proc Natl Acad Sci USA 90: 7696-7700, 1993.

30. Zvibel I, Bar-Zohar D, Kloog Y, Oren R and Reif S: The effect of Ras inhibition on the proliferation, apoptosis and matrix metalloproteases activity in rat hepatic stellate cells. Dig Dis Sci 53: 1048-1053, 2008.

31. Fischer AN, Fuchs E, Mikula M, Huber H, Beug $\mathrm{H}$ and Mikulits W: PDGF essentially links TGF-beta signaling to nuclear beta-catenin accumulation in hepatocellular carcinoma progression. Oncogene 26: 3395-3405, 2007.

32. Bromann PA, Korkaya H, Webb CP, Miller J, Calvin TL and Courtneidge SA: Platelet-derived growth factor stimulates Src-dependent mRNA stabilization of specific early genes in fibroblasts. J Biol Chem 280: 10253-10263, 2005.

33. Hennig A, Markwart R, Esparza-Franco MA, Ladds G and Rubio I: Ras activation revisited: Role of GEF and GAP systems Biol Chem 396: 831-848, 2015.

34. Bera A, Das F, Ghosh-Choudhury N, Li X, Pal S, Gorin Y, Kasinath BS, Abboud HE and Ghosh Choudhury G: A positive feedback loop involving Erk5 and Akt turns on mesangial cell proliferation in response to PDGF. Am J Physiol Cell Physiol 306: C1089-C1100, 2014.

35. Xiong C, Liu X and Meng A: The kinase activity-deficient isoform of the protein araf antagonizes Ras/mitogen-activated protein kinase (Ras/MAPK) signaling in the zebrafish embryo. J Biol Chem 290: 25512-25521, 2015.

36. Pan TL, Wang PW, Leu YL, Wu TH and Wu TS: Inhibitory effects of Scutellaria baicalensis extract on hepatic stellate cells through inducing G2/M cell cycle arrest and activating ERK-dependent apoptosis via Bax and caspase pathway. J Ethnopharmacol 139: 829-837, 2012

37. Park JH, Yoon J, Lee KY and Park B: Effects of geniposide on hepatocytes undergoing epithelial-mesenchymal transition in hepatic fibrosis by targeting TGF $\beta /$ Smad and ERK-MAPK signaling pathways. Biochimie 113: 26-34, 2015.

38. Osman I and Segar L: Pioglitazone, a PPAR $\gamma$ agonist, attenuates PDGF-induced vascular smooth muscle cell proliferation through AMPK-dependent and AMPK-independent inhibition of mTOR/p70S6K and ERK signaling. Biochem Pharmacol 101: 54-70, 2016

39. Margolis B, Zilberstein A, Franks C, Felder S, Kremer S, Ullrich A, Rhee SG, Skorecki K and Schlessinger J: Effect of phospholipase C-gamma overexpression on PDGF-induced second messengers and mitogenesis. Science 248: 607-610, 1990.

40. Mukherjee S, Duan F, Kolb MR and Janssen LJ: Platelet derived growth factor-evoked $\mathrm{Ca}_{2}{ }^{+}$wave and matrix gene expression through phospholipase $\mathrm{C}$ in human pulmonary fibroblast. Int J Biochem Cell Biol 45: 1516-1524, 2013.

41. Kojima N, Hori M, Murata T, Morizane Y and Ozaki H: Different profiles of $\mathrm{Ca}^{2+}$ responses to endothelin-1 and PDGF in live myofibroblasts during the process of cell differentiation. Br J Pharmacol 151: 816-827, 2007.

42. Benedetti A, Di Sario A, Casini A, Ridolfi F, Bendia E, Pigini P, Tonnini C, D'Ambrosio L, Feliciangeli G, Macarri G and Svegliati-Baroni G: Inhibition of the $\mathrm{NA}(+) / \mathrm{H}(+)$ exchanger reduces rat hepatic stellate cell activity and liver fibrosis: An in vitro and in vivo study. Gastroenterology 120: 545-556, 2001.

43. Di Sario A, Bendia E, Taffetani S, Marzioni M, Candelaresi C, Pigini P, Schindler U, Kleemann HW, Trozzi L, Macarri G and Benedetti A: Selective $\mathrm{Na}^{+} / \mathrm{H}^{+}$exchange inhibition by cariporide reduces liver fibrosis in the rat. Hepatology 37: 256-266, 2003.

44. Perkinton MS, Ip JK, Wood GL, Crossthwaite AJ and Williams RJ Phosphatidylinositol 3-kinase is a central mediator of NMDA receptor signalling to MAP kinase (Erk1/2), Akt/PKB and CREB in striatal neurons. J Neurochem 80: 239-254, 2002.

45. Fan H, Ma L, Fan B, Wu J, Yang Z and Wang L: Role of PDGFR- $\beta /$ $\mathrm{PI} 3 \mathrm{~K} / \mathrm{AKT}$ signaling pathway in PDGF-BB induced myocardial fibrosis in rats. Am J Transl Res 6: 714-723, 2014.

46. Niba ET, Nagaya H, Kanno T, Tsuchiya A, Gotoh A, Tabata C, Kuribayashi K, Nakano T and Nishizaki T: Crosstalk between PI3 kinase/PDK1/Akt/Rac1 and Ras/Raf/MEK/ERK pathways downstream PDGF receptor. Cell Physiol Biochem 31: 905-913, 2013.

47. Villarino AV, Kanno Y,Ferdinand JR and O'Shea JJ: Mechanisms of Jak/STAT signaling in immunity and disease. J Immunol 194: $21-27,2015$

48. Matsui F and Meldrum KK: The role of the Janus kinase family/signal transducer and activator of transcription signaling pathway in fibrotic renal disease. J Surg Res 178: 339-345, 2012.
49. Neeli I, Liu Z, Dronadula N, Ma ZA and Rao GN: An essential role of the Jak-2/STAT-3/cytosolic phospholipase A(2) axis in platelet-derived growth factor BB-induced vascular smooth muscle cell motility. J Biol Chem 279: 46122-46128, 2004.

50. Jiang JX, Mikami K, Venugopal S, Li Y and Török NJ: Apoptotic body engulfment by hepatic stellate cells promotes their survival by the JAK/STAT and Akt/NF-kappaB-dependent pathways. J Hepatol 51: 139-186, 2009.

51. Di Sario A, Bendia E, Svegliati-Baroni G, Marzioni M, Ridolfi F, Trozzi L, Ugili L, Saccomanno S, Jezequel AM and Benedetti A: Rearrangement of the cytoskeletal network induced by platelet-derived growth factor in rat hepatic stellate cells: Role of different intracellular signalling pathways. J Hepatol 36: 179-190, 2002.

52. Csak T, Bala S, Lippai D, Kodys K, Catalano D, Iracheta-Vellve A and Szabo G: MicroRNA-155 deficiency attenuates liver steatosis and fibrosis without reducing inflammation in a mouse model of steatohepatitis. PLoS One 10: e0129251, 2015.

53. Wei J,Feng L, LiZ, Xu G and Fan X: MicroRNA-21 activates hepatic stellate cells via PTEN/Akt signaling. Biomed Pharmacother 67: 387-392, 2013.

54. Kwiecinski M, Elfimova N, Noetel A, Töx U, Steffen HM, Hacker U, Nischt R, Dienes HP and Odenthal M: Expression of platelet-derived growth factor-C and insulin-like growth factor I in hepatic stellate cells is inhibited by miR-29. Lab Invest 92 : 978-987, 2012

55. Noetel A, Kwiecinski M, Elfimova N, Huang J and Odenthal M: microRNA are central players in anti- and profibrotic gene regulation during liver fibrosis. Front Physiol 3: 49, 2012.

56. Okada H, Honda M, Campbell JS, Takegoshi K, Sakai Y, Yamashita T, Shirasaki T, Takabatake R, Nakamura M, Tanaka T and Kaneko S: Inhibition of microRNA-214 ameliorates hepatic fibrosis and tumor incidence in platelet-derived growth factor $\mathrm{C}$ transgenic mice. Cancer Sci 106: 1143-1152, 2015.

57. Fu N, Niu X, Wang Y, Du H, Wang B, Du J, Li Y, Wang R, Zhang Y, Zhao S, et al: Role of LncRNA-activated by transforming growth factor beta in the progression of hepatitis $\mathrm{C}$ virus-related liver fibrosis. Discov Med 22: 29-42, 2016.

58. Yang JJ, Liu LP, Tao H, Hu W, Shi P, Deng ZY and Li J: MeCP2 silencing of LncRNA H19 controls hepatic stellate cell proliferation by targeting IGF1R. Toxicology 359-360: 39-46, 2016.

59. Yu F, Zheng J, Mao Y, Dong P, Lu Z, Li G, Guo C, Liu Z and Fan X: Long non-coding RNA growth arrest-specific transcript 5 (GAS5) inhibits liver fibrogenesis through a mechanism of competing endogenous RNA. J Biol Chem 290: 28286-28298, 2015.

60. Niu X, Fu N, Du J, Wang R, Wang Y, Zhao S, Du H, Wang B, Zhang Y, Sun D and Nan Y: miR-1273g-3p modulates activation and apoptosis of hepatic stellate cells by directly targeting PTEN in HCV-related liver fibrosis. FEBS Lett 590: 2709-2724, 2016.

61. Hyun J, Wang S, Kim J, Rao KM, Park SY, Chung I, Ha CS, Kim SW, Yun YH and Jung Y: MicroRNA-378 limits activation of hepatic stellate cells and liver fibrosis by suppressing Gli3 expression. Nat Commun 7: 10993, 2016.

62. Hao ZM, Fan XB, Li S, Lv YF, Su HQ, Jiang HP and Li HH: Vaccination with platelet-derived growth factor B kinoids inhibits $\mathrm{CCl}_{4}$-induced hepatic fibrosis in mice. J Pharmacol Exp Ther 342: 835-842, 2012.

63. Durez P, Vandepapeliere P, Miranda P, Toncheva A, Berman A, Kehler T, Mociran E, Fautrel B, Mariette X and Dhellin O, et al: Therapeutic vaccination with TNF-Kinoid in TNF antagonist-resistant rheumatoid arthritis: A phase II randomized, controlled clinical trial. PLoS One 9: e113465, 2014.

64. Jing Q, Yin T, Wan Y, Shi H, Luo S, Li M, Zhang H, He H, Liu S, $\mathrm{Li} \mathrm{H}$, et al: Interleukin-13 peptide kinoid vaccination attenuates allergic inflammation in a mouse model of asthma. Int J Mol Med 30: 553-560, 2012.

65. Delavallée L, Le Buanec H, Bessis N, Assier E, Denys A, Bizzini B, Zagury D and Boissier MC: Early and long-lasting protection from arthritis in tumour necrosis factor alpha (TNFalpha) transgenic mice vaccinated against TNFalpha. Ann Rheum Dis 67: 1332-1338, 2008.

66. Gounder MM, Lefkowitz RA, Keohan ML, D'Adamo DR, Hameed M, Antonescu CR, Singer S, Stout K, Ahn L and Maki RG: Activity of Sorafenib against desmoid tumor/deep fibromatosis. Clin Cancer Res 17: 4082-4090, 2011.

67. Zahavi T, Lanton T, Divon MS, Salmon A, Peretz T, Galun E, Axelrod JH and Sonnenblick A: Sorafenib treatment during partial hepatectomy reduces tumorgenesis in an inflammation-associated liver cancer model. Oncotarget 7: 4860-4870, 2016. 
68. Lin TsT, Gao DY, Liu YC, Sung YC, Wan D, Liu JY, Chiang T, Wang $\mathrm{L}$ and Chen Y: Development and characterization of sorafenib-loaded PLGA nanoparticles for the systemic treatment of liver fibrosis. J Control Release 221: 62-70, 2016.

69. Hong F, Chou H, Fiel MI and Friedman SL: Antifibrotic activity of sorafenib in experimental hepatic fibrosis: Refinement of inhibitory targets, dosing, and window of efficacy in vivo. Dig Dis Sci 58: 257-264, 2013.

70. Wang Y, Gao J, Zhang D, Zhang J, Ma J and Jiang H: New insights into the antifibrotic effects of sorafenib on hepatic stellate cells and liver fibrosis. J Hepatol 53: 132-144, 2010.

71. Hao H, Zhang D, Shi J, Wang Y, Chen L, Guo Y, Ma J, Jiang X and Jiang H: Sorafenib induces autophagic cell death and apoptosis in hepatic stellate cell through the JNK and Akt signaling pathways. Anticancer Drugs 27: 192-203, 2016.

72. Liu C, Yang Z, Wang L, Lu Y, Tang B, Miao H, Xu Q and Chen X: Combination of sorafenib and gadolinium chloride $(\mathrm{GdCl} 3)$ attenuates dimethylnitrosamine(DMN)-induced liver fibrosis in rats. BMC Gastroenterol 15: 159, 2015

73. Deng YR, Ma HD, Tsuneyama K, Yang W, Wang YH, Lu FT, Liu CH, Liu P, He XS, Diehl AM, et al: STAT3-mediated attenuation of $\mathrm{CCl} 4$-induced mouse liver fibrosis by the protein kinase inhibitor sorafenib. J Autoimmun 46: 25-34, 2013.

74. Qu K, Huang Z, Lin T, Liu S, Chang H, Yan Z, Zhang H and Liu C: New insight into the anti-liver fibrosis effect of multitargeted tyrosine kinase inhibitors: From molecular target to clinical trials. Front Pharmacol 6: 300, 2016.

75. Karuppagounder SS, Brahmachari S, Lee Y, Dawson VL, Dawson TM and Ko HS: The c-Abl inhibitor, nilotinib, protects dopaminergic neurons in a preclinical animal model of Parkinson's disease. Sci Rep 4: 4874, 2014.

76. Elsherbiny NM, El-Sherbiny M and Said E: Amelioration of experimentally induced diabetic nephropathy and renal damage by nilotinib. J Physiol Biochem 71: 635-648, 2015.

77. Shaker ME, Zalata KR, Mehal WZ, Shiha GE and Ibrahim TM: Comparison of imatinib, nilotinib and silymarin in the treatment of carbon tetrachloride-induced hepatic oxidative stress, injury and fibrosis. Toxicol Appl Pharmacol 252: 165-175, 2011.

78. Lemos DR, Babaeijandaghi F, Low M, Chang CK, Lee ST, Fiore D, Zhang RH, Natarajan A, Nedospasov SA and Rossi FM: Nilotinib reduces muscle fibrosis in chronic muscle injury by promoting TNF-mediated apoptosis of fibro/adipogenic progenitors. Nat Med 21: 786-794, 2015.

79. Shiha GE, Abu-Elsaad NM, Zalata KR and Ibrahim TM: Tracking anti-fibrotic pathways of nilotinib and imatinib in experimentally induced liver fibrosis: An insight. Clin Exp Pharmacol Physiol 41: 788-797, 2014.

80. Shaker ME, Shiha GE and Ibrahim TM: Comparison of early treatment with low doses of nilotinib, imatinib and a clinically relevant dose of silymarin in thioacetamide-induced liver fibrosis. Eur J Pharmacol 670: 593-600, 2011

81. Liu Y, Wang Z, Kwong SQ, Lui EL, Friedman SL, Li FR, Lam RW, Zhang GC, Zhang H and Ye T: Inhibition of PDGF, TGF- $\beta$, and Abl signaling and reduction of liver fibrosis by the small molecule Bcr-Abl tyrosine kinase antagonist Nilotinib. J Hepatol 55: 612-625, 2011.

82. Moawad EY: Predicting effectiveness of imatinib mesylate in tumors expressing platelet-derived growthfactors (PDGF-AA, PDGF-BB), stem cell factor ligands and their respective receptors (PDGFR- $\alpha$, PDGFR- $\beta$, and c-kit). J Gastrointest Cancer 46 : 272-283, 2015.

83. Kuo WL, Yu MC, Lee JF, Tsai CN, Chen TC and Chen MF: Imatinib mesylate improves liver regeneration and attenuates liver fibrogenesis in CCL4-treated mice. J Gastrointest Surg 16: 361-369, 2012.

84. Kim Y, Fiel MI, Albanis E, Chou HI, Zhang W, Khitrov G and Friedman SL: Anti-fibrotic activity and enhanced interleukin-6 production by hepatic stellate cells in response to imatinib mesylate. Liver Int 32: 1008-1017, 2012.

85. Iwamoto H, Nakamuta M, Tada S, Sugimoto R, Enjoji M and Nawata H: Platelet-derived growth factor receptor tyrosine kinase inhibitor AG1295 attenuates rat hepatic stellate cell growth. J Lab Clin Med 135: 406-412, 2000.

86. Hutson TE, Davis ID, Machiels JP, De Souza PL, Rottey S, Hong BF, Epstein RJ, Baker KL, McCann L, Crofts T, et al: Efficacy and safety of pazopanib in patients with metastatic renal cell carcinoma. J Clin Oncol 28: 475-480, 2010.

87. Eisen T, Joensuu H, Nathan PD, Harper PG, Wojtukiewicz MZ, Nicholson S, Bahl A, Tomczak P, Pyrhonen S, Fife K, et al: Regorafenib for patients with previously untreated metastatic or unresectable renal-cell carcinoma: A single-group phase 2 trial. Lancet Oncol 13: 1055-1062, 2012.
88. Rice AB, Moomaw CR, Morgan DL and Bonner JC: Specific inhibitors of platelet-derived grow th factor or epidermal growth factor receptor tyrosine kinase reduce pulmonary fibrosis in rats. Am J Pathol 155: 213-221, 1999.

89. Venè R, Tosetti F, Minghelli S, Poggi A, Ferrari N and Benelli R Celecoxib increases EGF signaling in colon tumor associated fibroblasts, modulating EGFR expression and degradation. Oncotarget 6: 12310-12325, 2015.

90. Soininen H, West C, Robbins J and Niculescu L: Long-term efficacy and safety of celecoxib in Alzheimer's disease. Dement Geriatr Cogn Disord 23: 8-21, 2007.

91. Raval M, Frank PG, Laury-Kleintop L, Yan G and Lanza-Jacoby S combined with atorvastatin prevents progression of atherosclerosis. J Surg Res 163: e113-e122, 2010.

92. Gao JH, Wen SL, Yang WJ, Lu YY, Tong H, Huang ZY, Liu ZX and Tang CW: Celecoxib ameliorates portal hypertension of the cirrhotic rats through the dual inhibitory effects on the intrahepatic fibrosis and angiogenesis. PLoS One 8: e69309, 2013.

93. Paik YH, Kim JK, Lee JI, Kang SH, Kim DY, An SH, Lee SJ, Lee DK, Han KH, Chon CY, et al: Celecoxib induces hepatic stellate cell apoptosis through inhibition of Akt activation and suppresses hepatic fibrosis in rats. Gut 58: 1517-1527, 2009

94. Ekor M, Odewabi AO, Kale OE, Adesanoye OA and Bamidele TO Celecoxib, a selective cyclooxygenase-2 inhibitor, lowers plasma cholesterol and attenuates hepatic lipid peroxidation during carbon-tetrachloride-associated hepatotoxicity in rats. Drug Chem Toxicol 36: 1-8, 2013.

95. Reina M and Martínez A: Is Silybin the best free radical scavenger compound in Silymarin? J Phys Chem B 120: 4568-4578, 2016.

96. Trappoliere M, Caligiuri A, Schmid M, Bertolani C, Failli P, Vizzutti F, Novo E, di Manzano C, Marra F, Loguercio C and Pinzani M: A component of sylimarin, exerts anti-inflammatory and anti-fibrogenic effects on human hepatic stellate cells. J Hepatol 50: 1102-1111, 2009.

97. Serviddio G, Bellanti F, Stanca E,Lunetti P,Blonda M, Tamborra R, Siculella L, Vendemiale G, Capobianco L and Giudetti AM Silybin exerts antioxidant effects and induces mitochondrial biogenesis in liver of rat with secondary biliary cirrhosis. Free Radic Biol Med 73: 117-126, 2014.

98. Malaguarnera M, Motta M, Vacante M, Malaguarnera G Caraci F, Nunnari G, Gagliano C, Greco C, Chisari G, Drago F and Bertino G: Silybin-vitamin E-phospholipids complex reduces liver fibrosis in patients with chronic hepatitis $\mathrm{C}$ treated with pegylated interferon $\alpha$ and ribavirin. Am J Transl Res 7: 2510-2518, 2015.

99. Bares JM, Berger J, Nelson JE, Messner DJ, Schildt S, Standish LJ and Kowdley KV: Silybin treatment is associated with reduction in serum ferritin in patients with chronic hepatitis C. J Clin Gastroenterol 42: 937-944, 2008.

100. Zhou M, Fan C and Tian N: Effects of curcumin on the gene expression profile of L-02 cells. Biomed Rep 3: 519-526, 2015.

101. Lian N, Jiang Y, Zhang F, Jin H, Lu C, Wu X, Lu Y and Zheng S Curcumin regulates cell fate and metabolism by inhibiting hedgehog signaling in hepatic stellate cells. Lab Invest 95: 790-803, 2015

102. Taverna S, Giallombardo M, Pucci M, Flugy A, Manno M, Raccosta S, Rolfo C, De Leo G and Alessandro R: Curcumin inhibits in vitro and in vivo chronic myelogenous leukemia cells growth: A possible role for exosomal disposal of miR-21. Oncotarget 6: 21918-21933, 2015.

103. El-Bahr SM: Curcumin regulates gene expression of insulin like growth factor, B-cell CLL/lymphoma 2 and antioxidant enzymes in streptozotocin induced diabetic rats. BMC Complement Altern Med 13: 368, 2013.

104. Zhang X, Chen M, Zou P, Kanchana K, Weng Q, Chen W, Zhong P, Ji J, Zhou H, He L and Liang G: Curcumin analog WZ35 induced cell death via ROS-dependent ER stress and G2/M cell cycle arrest in human prostate cancer cells. BMC Cancer 15: 866, 2015.

105. Lee HI, McGregor RA, Choi MS, Seo KI, Jung UJ, Yeo J, Kim MJ and Lee MK: Low doses of curcumin protect alcohol-induced liver damage by modulation of the alcohol metabolic pathway, CYP2E1 and AMPK. Life Sci 93: 693-699, 2013.

106. Zhao Y, Ma X, Wang J,He X,Hu Y,Zhang P,Wang R,Li R, Gong M, Luo $S$ and Xiao X: Curcumin protects against CCl4-induced liver fibrosis in rats by inhibiting HIF-1 $\alpha$ through an ERK-dependent pathway. Molecules 19: 18767-18780, 2014.

107. Xue J, Zhang X, Zhang C, Kang N, Liu X, Yu J, Zhang N, Wang H, Zhang L, Chen R, et al: Protective effect of Naoxintong against cerebral ischemia reperfusion injury in mice. J Ethnopharmacol 182: 181-189, 2016. 
108. Lv H, Wang L, Shen J, Hao S, Ming A, Wang X, Su F and Zhang Z: Salvianolic acid B attenuates apoptosis and inflammation via SIRT1 activation in experimental stroke rats. Brain Res Bull 115: 30-36, 2015.

109. Deng Y, Yang M, Xu F, Zhang Q, Zhao Q, Yu H, Li D, Zhang G, Lu A, Cho K, et al: Combined salvianolic acid B and ginsenoside $\mathrm{Rg} 1$ exerts cardioprotection against ischemia/reperfusion injury in rats. PLoS One 10: e0135435, 2015

110. Wang R, Yu XY, Guo ZY, Wang YJ, Wu Y and Yuan YF: Inhibitory effects of salvianolic acid $\mathrm{B}$ on $\mathrm{CCl}(4)$-induced hepatic fibrosis through regulating $\mathrm{NF}-\kappa \mathrm{B} / \mathrm{I} \kappa \mathrm{B} \alpha$ signaling. J Ethnopharmacol 144: 592-598, 2012.

111. Lv Z, Song Y, Xue D, Zhang W, Cheng Y and Xu L: Effect of salvianolic-acid B on inhibiting MAPK signaling induced by transforming growth factor- $\beta 1$ in activated rat hepatic stellate cells. J Ethnopharmacol 132: 384-392, 2010

112. Gao HY, Li GY, Lou MM, Li XY, Wei XY and Wang JH: Hepatoprotective effect of matrine salvianolic acid B salt on carbon tetrachloride-induced hepatic fibrosis. J Inflamm (Lond) 9: 16, 2012.

113. Xu H, Zhou Y, Lu C, Ping J and Xu LM: Salvianolic acid B lowers portal pressure in cirrhotic rats and attenuates contraction of rat hepaticstellate cells by inhibiting RhoA signaling pathway. Lab Invest 92: 1738-1748, 2012.

114. Marslin G, Revina AM, Khandelwal VK, Balakumar K, Prakash J, Franklin G and Sheeba CJ: Delivery as nanoparticles reduces imatinib mesylate-induced cardiotoxicity and improves anticancer activity. Int J Nanomedicine 10: 3163-3170, 2015.

115. Younis N, Shaheen MA and Abdallah MH: Silymarin-loaded Eudragit $\left({ }^{\circledR}\right)$ RS100 nanoparticles improved the ability of silymarin to resolve hepatic fibrosis in bile duct ligated rats. Biomed Pharmacother 81: 93-103, 2016.

116. Zhong H, Wang D, Wang N, Rios Y, Huang H, Li S, Wu X and Lin S: Combinatory action of VEGFR2 and MAP kinase pathways maintains endothelial-cell integrity. Cell Res 21: 1080-1087, 2011.
117. Srikanthan A, Ethier JL, Ocana A, Seruga B, Krzyzanowska MK and Amir E: Cardiovascular toxicity of multi-tyrosine kinase inhibitors in advanced solid tumors: A population-based observational study. PLoS One 10: e0122735, 2015.

118. Ghatalia P, Je Y, Mouallem NE, Nguyen PL, Trinh QD, Sonpavde G and Choueiri TK: Hepatotoxicity with vascular endothelial growth factor receptor tyrosine kinase inhibitors: A meta-analysis of randomized clinical trials. Crit Rev Oncol Hematol 93: 257-276, 2015.

119. Chrisoulidou A, Mandanas S, Margaritidou E, Mathiopoulou L, Boudina M, Georgopoulos K and Pazaitou-Panayiotou K: Treatment compliance and severe adverse events limit the use of tyrosine kinase inhibitors in refractory thyroid cancer. Onco Targets Ther 8: 2435-2442, 2015.

120. Reichenbach V,Fernández-VaroG,Casals G, OróD, Ros J,MelgarLesmes P, Weiskirchen R, Morales-Ruiz M and Jiménez W: Adenoviral dominant-negative soluble PDGFR $\beta$ improves hepatic collagen, systemic hemodynamics, and portal pressure in fibrotic rats. J Hepatol 57: 967-973, 2012.

121. Shah R, Reyes-Gordillo K, Arellanes-Robledo J, Lechuga CG, Hernández-Nazara Z, Cotty A, Rojkind M and Lakshman MR: TGF- $\beta 1$ up-regulates the expression of PDGF- $\beta$ receptor mRNA and induces a delayed PI3K-, AKT- and p70(S6K)-dependent proliferative response in activated hepatic stellate cells. Alcohol Clin Exp Res 37: 1838-1848, 2013.

122. Bai Q, An J, Wu X, You H, Ma H, Liu T, Gao N and Jia J: HBV promotes the proliferation of hepatic stellate cells via the PDGF-B/PDGFR- $\beta$ signaling pathway in vitro. Int J Mol Med 30: 1443-1450, 2012.

123. Liang CC, Liu CH, Chung CS, Lin CK, Su TH, Yang HC, Liu CJ, Chen PJ, Chen DS and Kao JH: Advanced hepatic fibrosis and steatosis are associated with persistent alanine aminotransferase elevation in chronic hepatitis $\mathrm{C}$ patients negative for hepatitis $\mathrm{C}$ virus RNA during pegylated interferon plus ribavirin therapy. $\mathrm{J}$ Infect Dis 211: 1429-1436, 2015. 